TEACHING TACTIC

\title{
The Accountability for Daily Readings Quiz
}

\section{Roshan Iqbal \\ Agnes Scott College}

\section{The context}

Introductory religious studies courses that also aim to develop critical reading and writing skills.

\section{The pedagogical purpose}

This tactic creates accountability for reading. It is hard to make students read the assigned material but if students don't read class discussions and student writing suffer. In my introductory level classes, I combat this by assigning quizzes at the start of each class session. Since quizzes are worth sixty percent of their grade, they have to read or their grades suffer. I do drop the two lowest scores of the quiz.

\section{Description of the strategy}

I design quizzes around ideas I would like to discuss in class. They become a map of the most important points in the reading, or put differently, my lesson plan. The quizzes are open book which brings the anxiety down but I only allot ten minutes, so if they haven't read, they won't do well. The ten to fifteen questions on the quiz will be of three types: true and false, select the right answer, and fill in the blank. I start the class with the quiz. Once students have attempted it, we discuss the answers. Along with my being able to bring up the essential points in the reading, the quiz also alerts the students to gaps in their knowledge, given that they find out right away which things they do not know or misunderstood. These daily quizzes create a lot of grading work for me. Though, I think the reward of having students who have attempted the readings in my class is worth all the hours spent grading and recording the grade.

\section{Why it is effective}

The daily quiz routine is beneficial in four ways. They force students to do the readings. Studies have shown a positive correlation between compliance in reading and quizzes (Hoeft 2012, Marcel 2008, Maurer and Longfield 2015). The quizzes bring students into the classroom. Taking the quiz helps students focus. Finally, they identify student progress immediately, from class to class. The daily quiz motivates most students, most of the time, to do their reading. 